\title{
16. The Fine Structure of Germinating Resting Spores of Olpidium brassicae
}

\author{
By Chuji HIRUKI \\ Department of Plant Science, University of Alberta \\ Edmonton, Alberta, Canada T6G 2P5 \\ (Communicated by Naohide Hiratsuka, M. J. A., May 13, 1991)
}

\begin{abstract}
The resting spores of Olpidium brassicae in young root tissues of tobacco plants, observed in time sequence with a scanning electron microscope after freezefracturing, were first smooth spheres later developing ridges with pentamer and hexamer facets on the surface. Transmission electron microscope studies showed that the wall of mature resting spores consisted of three layers: inner, intermediate and outer. The cytoplasm was dense and contained many lipid-like bodies at the periphery. As individual zoospores developed fully, an exit tube containing membrane-bound vesicles was formed by the protrusion of the inner layer through the intermediate and outer layers of the wall. The result of computer image analysis supported these observations.
\end{abstract}

Key words: Chytridiales; virus vector; electron microscopy.

Introduction. Olpidium brassicae, one of the common root-infecting soil-borne fungi, is one of the best known as a vector of certain plant viruses. The fungus is endobiotic and holocarpic. The life-cycle of the fungus is simple and has three stages, i.e. zoospore, zoosporangium and resting spore. Zoosporangia and resting spores develop in the epidermal and cortical cells of plant roots following infection of the cells by zoospores. While the ultrastructure of zoospores and zoosporangia of $O$. brassicae has been studied in detail (Temmink and Campbell, 1968, 1969a, 1969b; Lesemann and Fuchs, 1970a, 1970b; Temmink, 1971), information concerning the resting spore formation and germination at the ultrastructural level has been limited (Hiruki and Alderson, 1976; Hiruki, 1987, 1990). This paper reports the results of observations on the fine structure of germinating resting spores of $O$. brassicae by scanning and transmission electron microscopy.

Materials and methods. Culture of $O$. brassicae: The tobacco strain of $O$. brassicae used in this study was originally obtained from a single isolate from tobacco after repeated culture on the roots of cowpea (Hiruki, 1965). In some experiments $O$. brassicae in tobacco seedlings fully infected with tobacco stunt virus (TSV) was used. The O. brassicae isolates were cultured on roots of tobacco seedlings grown in sterilized quartz sand, and watered with a half-strength Hoagland's nutrient solution (Hoagland and Arnon, 1950). Plants in microincubators (Hiruki, 1969) were maintained in growth cabinets at $17^{\circ} \mathrm{C}$ with a $16 \mathrm{~h}$ light period. During the first week the roots were examined microscopically at $24 \mathrm{~h}$ intervals for the development of resting spores, and thereafter weekly intervals.

Scanning electron microscopy. Olpidium resting spores in young root tissue were fixed for $1 \mathrm{~h}$ at $22^{\circ} \mathrm{C}$ in $0.1 \mathrm{M}$ phosphate buffer $\mathrm{pH} 7.0$ containing $2 \%$ glutaraldehyde and $2 \%$ formaldehyde, washed with distilled water, postfixed in $2 \%$ osmium tetroxide for $30 \mathrm{~min}$, washed again and then freeze-dried in liquid nitrogen. Some roots containing resting spores were freeze-fractured after fixation. Fixed roots were frozen rapidly in Freon 13 and fractured with a pre-cooled scalpel. The fractured roots were transferred into liquid nitrogen, freeze-dried and examined with a Cambridge Stereoscan S4. 
Transmission electron microscopy. Olpidium resting spores in root tissue, $2-3 \mathrm{~mm}$ long, were fixed overnight at $4^{\circ} \mathrm{C}$ in $0.1 \mathrm{M}$ phosphate buffer $\mathrm{pH} 7.0$, containing $2 \%$ glutaraldehyde and $2 \%$ formaldehyde. After rinsing in the same buffer solution for $30 \mathrm{~min}$, and then in distilled water, the samples were post-fixed with $2 \%$ osmium tetroxide for $4 \mathrm{~h}$. They were embedded in Araldite after dehydration. Thin sections were stained with uranyl acetate and lead citrate. Micrographs were taken with a Philips Model 200 electron microscope operated at $60 \mathrm{kv}$.

Computer image analysis. Image analysis was done on a Trachor Northern 5500 X-ray analyzer.

Results. Ridges of resting spores of $O$. brassicae began to form $48 \mathrm{~h}$ after infection and at $96 \mathrm{~h}$ resting spores, having clearly recognizable characteristic thick undulated walls, were observed. The ridges were more pronounced at $120 \mathrm{~h}$, often showing a regular combination of pentamers and hexamers (Fig. 1). Resting spores were present in the cells of the epidermis and cortex of freeze-fractured roots up to 4 weeks after root inoculation with zoospores. No resting spores were observed in xylem or phloem elements. A section of resting spore at 4 weeks showed the presence of numerous zoospores enclosed in the thick walls (Fig. 2). The resting spore wall was composed of at least three distinct layers: inner, intermediate and outer (Figs. 2 and 3). The formation of an exit tube was indicated by the softening and partial breakdown of the fungal wall (Fig. 2). As individual zoospores were developed fully, an exit tube was formed by the protrusion of the inner layer through

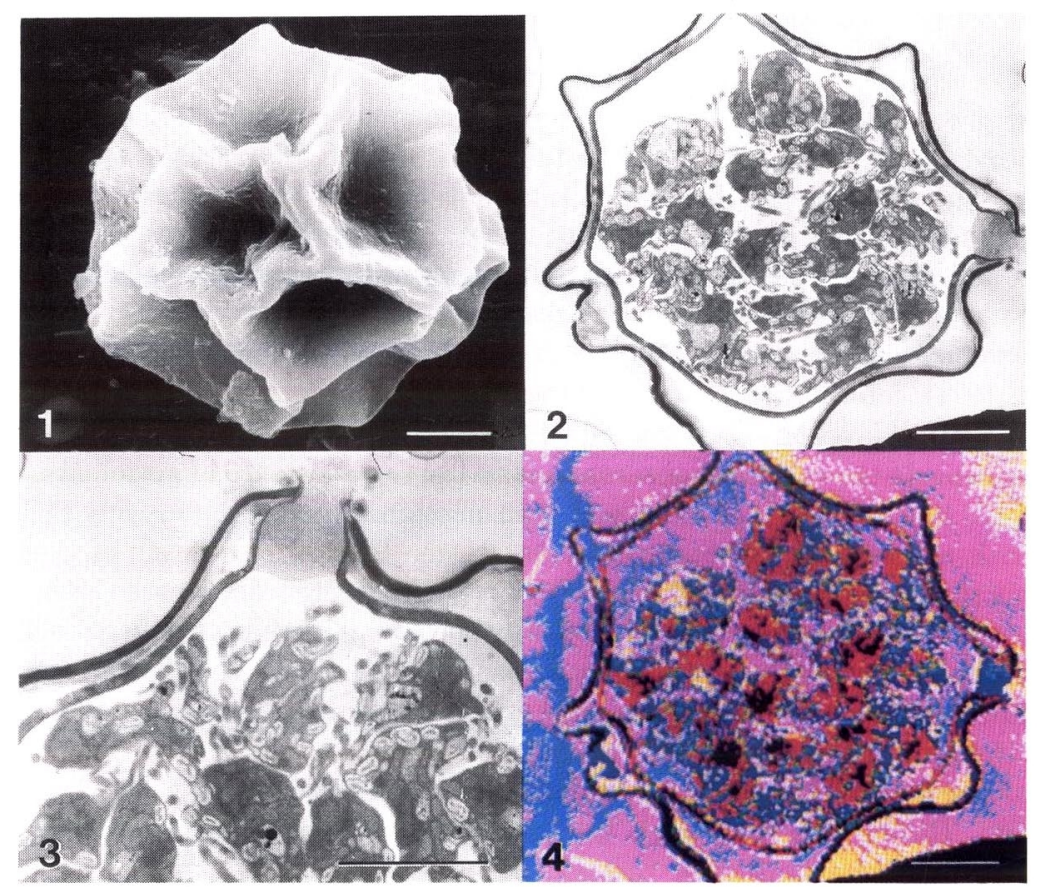

Fig. 1. Olpidium brassicae resting spore showing pronounced ridges 120 hours after inoculation with zoospores.

Fig. 2. O. brassicae resting spore containing fully developed zoospores.

Fig. 3. An enlarged view of an exit tube in the resting spore of $O$. brassicae. Note the presence of plug material (membrane-bound cytoplasmic vesicles).

Fig. 4. Computer image analysis of $O$. brassicae resting spore shown in Fig. 2. Bars, $3 \mu \mathrm{m}$. 
the intermediate and outer layers of the wall. The short exit tube contained numerous membrane-bound cytoplasmic vesicles that served as a plug until the release of zoospores started (Fig. 3). The presence of plug material at the very short exit tube indicated that the development of zoospores was complete and their release was imminent (Fig. 3). Image analysis of the thin section of an Olpidium resting spore clearly delineated the internal ultrastructure (Fig. 4).

Discussion. This study has affirmed and extended the previous study on the resting spores of O. brassicae (Hiruki and Alderson, 1976; Hiruki, 1987, 1990). The wall of Olpidium resting spores was laid down exterior to the thallus plasmalemma, and the wall components appeared amorphous during the initial stages of its formation. However, as characteristic ridges started to develop, at least three layers of the wall were recognizable. The pentamer and hexamer facets delineated by the wall ridges probably provide structural stability as well as flexibility to allow contraction and expansion of the resting spore in response to changing environmental conditions. The presence of numerous membrane-bound vesicles concentrated at the site of the breakdown of the Olpidium resting spore wall suggests its involvement in the process leading to the formation of an exit tube. Similar vesicles have been observed in the germinating zoosporangia of $O$. brassicae (Temmink, 1971) and of Polymyxa betae (D'Ambra and Mutto, 1977), in the penetration structure of several fungi (Sargent et al., 1973; McKeen, 1974), in spore germination (Murray and Maxwell, 1974; Hemmes and Wong, 1975) and in hyphal elongation (Grove and Bracker, 1970; Beckett et al., 1974). Thus, they seem to occur widely both in wall dissolution and its synthesis. In fact, D'Ambra and Mutto (1976) suggested that these vesicles may contain substances responsible for both fungus and host cell wall softening which permits the exit tube to grow out.

The recovery of TSV has been reported for viruliferous Olpidium resting spores air-dried for 20 years (Hiruki, 1987). The persistence of TSV in Olpidium-infested soil is explained by the internal association of TSV with resting spores. Moreover, TSV in the resting spores has been shown to withstand not only unfavourable environmental conditions but also certain drastic treatments such as strong acid, alkali and UV irradiation (Hiruki, 1987). These results suggest that the genome of TSV is firmly associated with $O$. brassicae in a protective manner. Although a partial genomic RNA of TSV was detected in the zoospores isolated from TSV-infected tobacco (Hiruki and Masri, 1987), the mode of its association with resting spores remains to be determined.

Factors governing the germination of Olpidium resting spores are unknown at present. Understanding of stimulatory conditions for the germination of resting spores will be very useful in developing practical methods for disease management of tobacco stunt in the field.

Acknowledgements. This work was supported by an operating grant (A3843) from the Natural Sciences and Engineering Council of Canada. Thanks are due to Mr. G. D. Braybrook for assistance in scanning electron microscopy and to Mr. D. Hildebrandt for computer image analysis.

\section{References}

Beckett, A. et al. (1974): An atlas of fungal ultrastructure. Longman Group Ltd., London. D'Ambra, V., and Mutto, S. (1977): Can. J. Bot., 55, 831-839.

Grove, S. N., and Bracker, C. E. (1970): J. Bacteriol., 104, 989-1009.

Hemmes, D. E., and Wong, L. D. S. (1975): Can. J. Bot., 53, 2945-2957.

Hiruki, C. (1965): Virology, 25, 541-549.

- (1969): ibid., 39, 333-334. 
(1987): Plant Pathol., 36, 224-228.

(1990): Proc. First Symposium of the Internat. Working Group on Plant Viruses with

Fungal Vectors. Schriftenreihe Deut. Phytomed. Gessell., 1, 163-166.

Hiruki, C., and Alderson, P. G. (1976): Can. J. Bot., 54, 2820-2826.

Hiruki, C., and Masri, S. A. (1987): VII Internat. Cong. Virology, Abst. R31.7.

Hoagland, D. R., and Arnon, D. I. (1950): Calif. Univ. Agr. Expt. Sta. Bull., no. 347.

Lesemann, D. E., and Fuchs, W. H. (1970a): Arch. Mikrobiol., 71, 9-19.

- (1970b): ibid., 71, 20-30.

McKeen, W. E. (1974): Phytopathology, 64, 461-467.

Murray, G. M., and Maxwell, D. P. (1974): Can. J. Bot., 52, 2335-2340.

Sargent, J. A. et al. (1973): Physiol. Plant Pathol., 3, 231-239.

Temmink, J. H. M. (1971): Meded. Landbouwhogeschool. Wageningen, 71-6, 1-135.

Temmink, J. H. M., and Campbell, R. N. (1968): Can. J. Bot., 46, 951-956.

(1969a): ibid., 47, 227-231.

(1969b): ibid., 47, 421-424. 